\title{
Viabilidade da seleção precoce de Pinus taeda L. em diâmetro a altura do peito em programa de melhoramento genético
}

\author{
Viability of premature selection of Pinus taeda L. in \\ diameter breast height in genetic improvement program
}

\author{
Rodrigo Toledo Coutinho', João Carlos Bespalhok Filho², \\ Roberto Fritsche Neto $^{3}$ e Caroline Frizzo ${ }^{4}$
}

\begin{abstract}
Resumo
A seleção dos genótipos superiores de Pinus taeda L. por meio de ensaios genéticos de campo requerem vários anos de duração. Com isto, vários pesquisadores investiram esforços na avaliação da seleção em idades anteriores à idade final de rotação. O objetivo deste trabalho foi analisar a viabilidade da seleção em progênies de meios-irmãos de Pinus taeda L., na idade de oito anos (seleção precoce) comparando com a seleção aos quinze anos (seleção tardia), visando definir qual a melhor estratégia. Para isto, os parâmetros e os ganhos genéticos, para a variável diâmetro à altura do peito (DAP), foram preditos entre e dentro das progênies em ensaios localizados nos municípios de Campo do Tenente, Sengés e Jaguariaíva, estado do Paraná, Brasil. Foram observadas correlações significativas para o ordenamento das progênies e para correlação linear dos valores genéticos aditivos preditos entre as idades de oito e quinze anos. As herdabilidades obtidas neste estudo foram maiores em Campo do Tenente, onde observou-se maior crescimento, coincidindo também com o local de seleção das matrizes das progênies. Para o ensaio de Campo do Tenente a seleção com oito anos apresentou o mesmo ganho genético predito em relação a idade de quinze anos, tanto para a seleção dos genitores como seleção dos melhores indivíduos. Para o ensaio Morungava, município de Sengés, com as condições edafoclimáticas similares a Campo do Tenente, porém mais distante do local de seleção das matrizes, foi observado sucesso apenas na seleção precoce dos melhores indivíduos, visto que os genitores selecionados na seleção precoce não apresentaram diferença estatística. Para a seleção dos melhores indivíduos de forma precoce aos oito anos indica-se utilizar a restrição de número máximo de indivíduos por genitor por apresentar mesmo resultado estatístico porém com maior variabilidade genética. Para o ensaio Mocambo, também no município de Sengés, porém com condições edafoclimáticas muito distintas dos demais, não foi possível observar diferenças estatísticas tanto na seleção dos genitores como na seleção dos melhores indivíduos.
\end{abstract}

Palavras-chave: Modelos Mistos; Predição Genética; Melhoramento; Progênies.

\begin{abstract}
The superior genotypes selection of Pinus taeda L. using genetic field trials require many years, due to the rotation age of commercial plantations, which consumes a lot of financial resources. Regarding this, many researchers have put their efforts in evaluate the selection in early ages prior to the final age of rotation. The goals of this study are to estimate, at the early age of eight years and final rotation age of fifteen years, the genetic parameters and the predicted genetic gains between and within the progenies of Pinus taeda L. half-sib family, with experiments established in three distinct locations in the state of Paraná, Brazil. There were significant correlations observed for the progenies ranking and for the linear correlation of the additive genetic gain between the age of eight and fifteen years. The obtained heritability in this study were greater in Campo do Tenente, were it was observed a greater growth, also concurring with the location of the evaluated half-sib family selection. For the Campo do Tenente experiment, the eight years old measures displayed the same predicted genetic gain of those from the fifteen years old measures, for either the parents or the best individual selection. For the Morungava experiment, located in the municipality of Senges, having similar soil and climate conditions of Campo do Tenente, however further away from the parents selection location, it was only possible to succeed in the best

${ }^{1}$ Pesquisador Doutor. Arauco do Brasil, Pesquisa e Desenvolvimento. Rua Roberto Hauer, 160 - 81610-180 - Curitiba, PR, Brasil. E-mail: tehudi@gmail.com

2Professor Associado do Departamento de Fitotecnia e Fitossanitarismo. UFPR - Universidade Federal do Paraná. Rua dos Funcionários, 1540 - 80035-050 - Curitiba, PR, Brasil. E-mail: bespa@ufpr.br

3Professor Associado do Departamento de Genética. USP - Universidade de São Paulo / ESALQ - Escola Superior de Agricultura "Luiz de Queiroz". Av. Pádua Dias, 11 - São Dimas - 13418900 - Piracicaba, SP, Brasil. E-mail: roberto.neto@usp.br ${ }^{4}$ Doutoranda em Agronomia. UFPR - Universidade Federal do Paraná. Rua dos Funcionários, 1540 - 80035-050 - Curitiba, PR, Brasil. E-mail: carolinefrizzo@hotmail.com
\end{abstract}

Sci. For., Piracicaba, v. 45, n. 113, p. 205-219, mar. 2017 DOI: dx.doi.org/10.18671/scifor.v45n113.21 
individual selection at eight years old age, whereas the parents selection at this age have not showed significant statistical difference apart the control. For the best individual selection at early age, it is recommended to utilize the maximum number of individuals per genitor restriction, due to showing the same statistical results of the selection at fifteen years old, but with greater genetic variability. For the Mocambo experiment, also in the municipality of Senges, but with soil and climate conditions very different, it was not possible to detect statistical differences for neither the parents nor the best individual selection. Keywords: Mixed Models, Genetic Prediction, Improvement, Progenies.

\section{INTRODUÇÃO}

O plantio do gênero Pinus no Brasil engloba aproximadamente 1,6 milhões de hectares dos quais aproximadamente 1,2 milhões de hectares, 76\%, estão localizados nos estados do Paraná e de Santa Catarina. Esta produção florestal muito utilizada pelo setor de painéis de madeira industrializada teve crescimento médio de 8\% a.a entre 2012 e 2013 (IBÁ, 2015). Com este aumento expressivo existe a necessidade cada vez maior de aumentar a produção florestal na mesma proporção para possibilitar o abastecimento destas indústrias. Desta forma o melhoramento genético do Pinus taeda L., principal espécie utilizada, tem sido prioridade e de grande importância. Um segundo fator para aumentar a produtividade florestal se deve pelas dificuldades que as empresas de base florestal dos estados do Paraná e Santa Catarina têm para a compra de novas áreas.

Todo melhorista enfrenta o dilema entre predizer e recomendar genótipos superiores antes da idade de rotação ou aguardar o final do ensaio. A seleção dos genótipos superiores de Pinus taeda L. por meio de ensaios genéticos de campo requerem vários anos de duração, devido à idade de rotação dos plantios comerciais serem de aproximadamente quinze anos. Com isto vários pesquisadores investiram esforços em avaliar a seleção em idades precoces anteriores à idade de quinze anos, como Paludzyszyn Filho et al., (2002) que analisaram a seleção genética de Pinus taeda L. em duas idades distintas em ensaios genéticos implantados no estado do Paraná.

Estes últimos autores concluíram que os ganhos genéticos aditivos preditos foram similares para as duas idades estudadas, revelando alto potencial para a seleção precoce, e o mais importante que aguardar a seleção na idade final de rotação não supera o benefício de se obter oferta antecipada de sementes com a seleção precoce.

Conforme necessidade e contexto exposto acima, os objetivos principais deste trabalho foram analisar a seleção precoce, predizendo os ganhos genéticos dos genitores e melhores indivíduos de progênies de meios-irmãos de Pinus taeda L., na idade de oito anos (seleção precoce) comparando com a seleção aos quinze anos (seleção tardia), visando definir qual a melhor estratégia a ser adotada em um programa de melhoramento genético.

\section{MATERIAL E MÉTODOS}

Os ensaios genéticos foram implantados com progênies de meios-irmãos de Pinus taeda L., com sementes coletadas de 70 matrizes selecionadas fenotipicamente em plantios comerciais com cinco anos de idade com critério de seleção de crescimento e sanidade. Esta seleção das matrizes foi realizada em Campo do Tenente, PR, no ano de 1994 com intensidade de seleção de aproximadamente 1 matriz para cada 6.143 árvores candidatas. A procedência das sementes que formaram as mudas deste plantio comercial, onde se realizou esta seleção, foi o pomar clonal de primeira geração de uma empresa florestal sediada em Três Barras, estado de Santa Catarina. Muito provável que este pomar foi formado com seleção de matrizes em plantios comerciais localizados nesta mesma região de Três Barras, porém a origem genética do plantio destas matrizes são os estados americanos de Carolina do Sul, Carolina do Norte e Geórgia. A localização das seleções e ensaios estão apresentados na Figura 1.

Após a seleção de 1994 das 70 matrizes com cinco anos de idade se iniciou a coleta das sementes no mesmo local onde as matrizes foram selecionadas, até que no ano de 1997 se obteve lotes de sementes que possibilitaram a implantação dos três ensaios de progênies de polinização aberta (progênies de meios-irmãos). Devido à baixa oferta de sementes e o delineamento estatístico adotado, ocorreu um desbalanceamento dos tratamentos entre os locais e, desta forma, os ensaios locali- 
zados em Campo do Tenente, Morungava e Mocambo foram implantados com respectivamente 60, 66 e também 66 progênies cada. Adicionalmente, em todos os ensaios foram implantadas quatro testemunhas sendo: (i) mudas formadas com sementes de polinização aberta do pomar clonal da empresa localizada no município de Três Barras, apresentada com o código 71 nos resultados (ii) mudas formadas com sementes de polinização aberta de uma área de produção de sementes localizada no município de Itapeva, estado de São Paulo, apresentada com o código 72 (iii) mudas formadas com sementes de polinização aberta de um pomar clonal de sementes localizado no município de Jaguariaíva com código 73 e (iv) mudas formadas com sementes de polinização controlada deste último pomar clonal de sementes do município de Jaguariaíva com código 74.

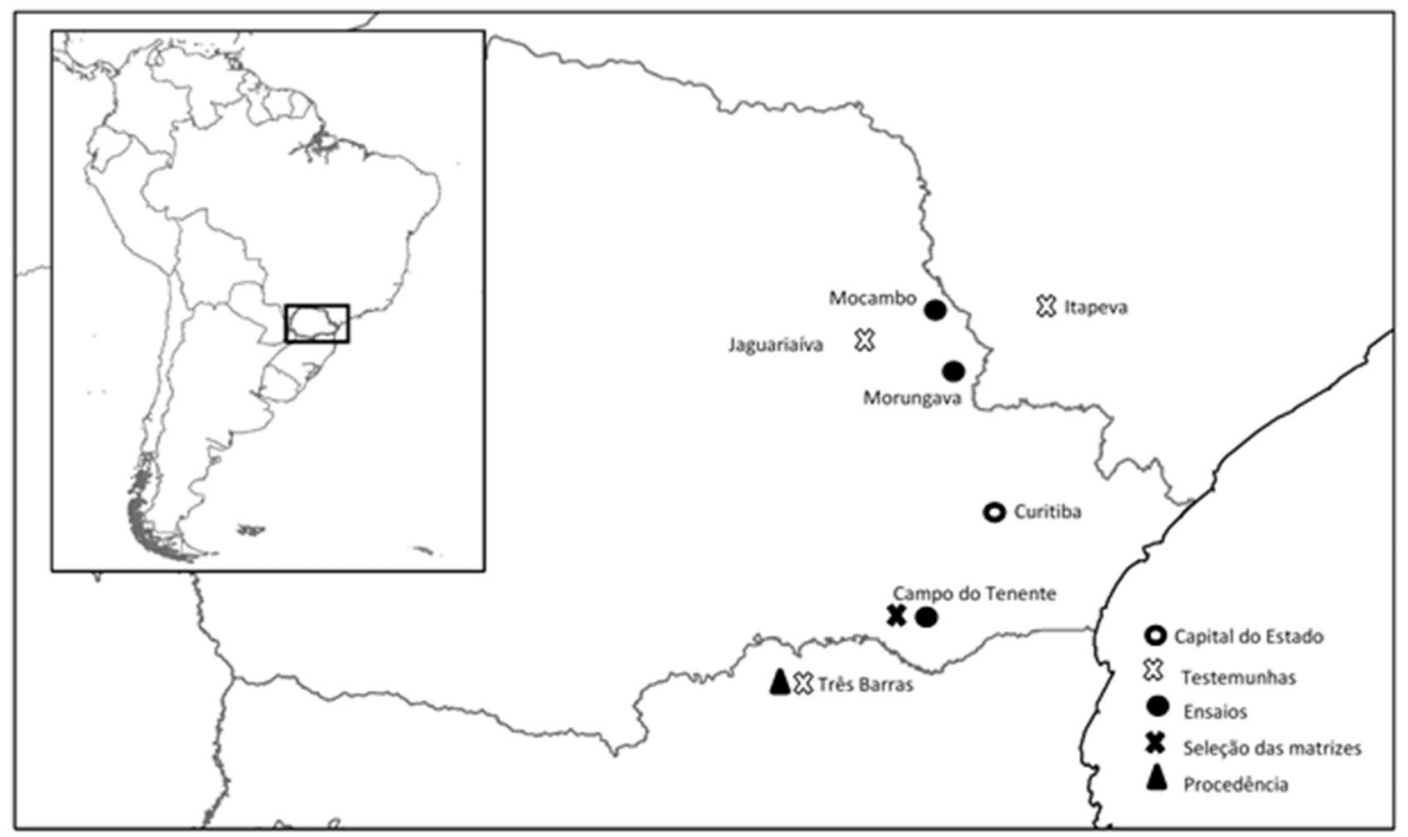

Figura 1. Mapa de localização dos ensaios implantados em Campo do Tenente, Morungava e Mocambo, com o local da procedência das matrizes no município de Três Barras, localização da seleção fenotípica das matrizes que geraram as progênies meios-irmãos em Campo do Tenente, e localização das testemunhas utilizadas.

Figure 1. Location map of the tests performed in Campo do Tenente, Morungava and Mocambo, presenting the origin of the matrices locations in the municipality of Três Barras, the location of the phenotypic selection of the matrices that generated the half-sibling progenies in Campo do Tenente, and the location of the control used.

Os ensaios foram implantados com parcelas lineares de cinco plantas em blocos ao acaso com oito repetições, totalizando em cada local quarenta plantas por tratamento. O espaçamento utilizado foi de 3,0 metros (m) entre linhas e 2,0 m entre plantas, visando manejo sem desbastes e corte raso aos quinze anos. Estes três ensaios implantados em 1998 foram avaliados no ano de 2006 com oito anos de idade e no ano de 2013 com a idade de rotação final de quinze anos. As avaliações foram medição direta do diâmetro a altura do peito (DAP) e estimativa da altura total da árvore (Ht) com hipsômetro. Com estas duas variáveis foi estimado o volume total da árvore com equação polinomial de $5^{\circ}$. grau utilizada de forma operacional na empresa proprietária dos ensaios.

As caracterizações edafoclimáticas dos ensaios de progênies estão apresentadas na Tabela 1.

O teste de progênie no município de Campo do Tenente está localizado a $870 \mathrm{~m}$ de altitude com solo do tipo Cambissolo húmico ta alumínico típico textura argilosa com profundidade $120 \mathrm{~cm}+$ conforme classificação brasileira de solos (EMBRAPA, 2013). A geologia de origem deste solo é o Grupo Itararé, porém com sedimentos do tipo folhelhos (MINEROPAR, 2006). O clima segundo Koeppen é Cfb, ou seja, sempre úmido, apresentando nos três meses mais frios com temperatura média do ar entre três graus negativos a dezoito graus positivos, e também com o mês mais quente com temperatura média do ar menor que $22^{\circ} \mathrm{C}$, e demais onze meses com temperatura média do ar maior que $10^{\circ} \mathrm{C}$. Este ensaio está localizado no fitogeografia Floresta Ombrófila Mista que também é conhecido como Mata de Araucárias (MAACK, 2002). Ainda segundo este último autor temos mais de cinco geadas noturnas por ano e raramente neve. A precipitação média anual com série histórica de 1977 a 2006 para este ensaio é de 1.500 a 1.600 mm (CPRM, 2006). 
Tabela 1. Localização dos testes de progênies de meios-irmãos de Pinus taeda L., bem como as condições edafoclimáticas dos locais. Fonte: do autor

Table 1. Localization of the progeny tests of of half-siblings of Pinus taeda L., as well as the edaphoclimatic conditions of the sites. Source: Author.

\begin{tabular}{|c|c|c|c|}
\hline Local & Campo do Tenente & Morungava & Mocambo \\
\hline Município & Campo do Tenente & \multicolumn{2}{|c|}{ Sengés } \\
\hline Geologia & $\begin{array}{l}\text { Grupo Itararé origem sedimen- } \\
\text { tar folhelhos }\end{array}$ & $\begin{array}{l}\text { Grupo Itaiaoca origem meta- } \\
\text { mórfica }\end{array}$ & $\begin{array}{l}\text { Grupo Itararé origem sedimen- } \\
\text { tar arenito }\end{array}$ \\
\hline Clima & \multicolumn{2}{|c|}{ Cfb Clima temperado } & Cfa Clima temperado quente \\
\hline Precipitação & 1.500 a $1.600 \mathrm{~mm}$ & \multicolumn{2}{|c|}{1.300 a $1.400 \mathrm{~mm}$} \\
\hline Solo & $\begin{array}{l}\text { Cambissolo húmico ta alumíni- } \\
\text { co típico textura argilosa profun- } \\
\text { didade } 120 \mathrm{~cm}+\end{array}$ & $\begin{array}{l}\text { Cambissolo húmico tb distrófico } \\
\text { típico textura argilosa casca- } \\
\text { Ihenta profundidade } 120 \mathrm{~cm}+\end{array}$ & $\begin{array}{l}\text { Cambissolo háplico tb distrófico } \\
\text { típico textura média prof. } 100 \mathrm{~cm}\end{array}$ \\
\hline Altitude & $870 \mathrm{~m}$ & $970 \mathrm{~m}$ & $715 \mathrm{~m}$ \\
\hline Fitogeografia & \multicolumn{2}{|c|}{ Floresta Ombrófila Mista } & Cerrado \\
\hline
\end{tabular}

O teste de progênie Morungava localizado no município Sengés está a $970 \mathrm{~m}$ de altitude com solo Cambissolo húmico tb distrófico típico textura argilosa cascalhenta com profundidade 120 $\mathrm{cm}+$ conforme classificação brasileira de solos (EMBRAPA, 2013). A geologia de origem deste solo é o Grupo Itaiaoca, porém com sedimentos de rochas metamórficas (MINEROPAR, 2006). O clima e fitogeografia sãos os mesmos de Campo do Tenente, ou seja, conforme descrito anteriormente, porém a precipitação média anual para este ensaio é de 1.300 a $1.400 \mathrm{~mm}$ (CPRM, 2006), ou seja, no mínimo $100 \mathrm{~mm}$ menor que a precipitação de Campo do Tenente.

O teste de progênie Mocambo também se localiza no município de Sengés porém, além de diferenças em relação a Morungava na altitude, geologia e solos, apresenta também clima e fitogeografia muito peculiares. A altitude é a menor entre os demais ensaios com $715 \mathrm{~m}$ de altitude e o solo é do tipo Cambissolo háplico tb distrófico típico textura média com profundidade $100 \mathrm{~cm}$ conforme classificação brasileira de solos (EMBRAPA, 2013). O Clima é do tipo Cfa, ou seja, clima temperado quente com o mês mais quente com temperatura média do ar maior que $22^{\circ} \mathrm{C}$, e o fitogeografia no local do ensaio é Cerrado que também descrito por Maack (2002) como Campos Cerrados ou estepes arbustivas. Segundo este último autor o município de Sengés localiza-se em meio a estes Campos de Cerrados. Embora a distância em linha do ensaio localizado na fazenda Morungava e Mocambo ser de aproximadamente $50 \mathrm{~km}$ e pertencerem ao mesmo município de Sengés, ambos os ensaios estão em clima, fitogeografia, geologia e solo, e altitude muito distintos, pois nesta região existe a transição do primeiro para o segundo planalto do Paraná e também de um clima típico sub-tropical do clima típico tropical.

Para aumentar a acurácia e mitigar os efeitos das árvores vizinhas mortas, foi realizado a correção do índice de falhas (IF) segundo Pires et al., (2011) calculando o IF de cada árvore e utilizando como covariável nas análises estatísticas. Pelo espaçamento utilizado nos ensaios o IF foi calculado pela equação: $\mathrm{IF}=\left(1,0 \times \mathrm{n}^{\circ}\right.$. de falhas na vizinhança da Linha de plantio $)+\left(0,6667 \times \mathrm{n}^{\circ}\right.$. de falhas na vizinhança na entrelinha ao lado $)+\left(0,5547 \mathrm{x} \mathrm{n}^{\circ}\right.$. de falhas na vizinhança na diagonal $)$.

Neste trabalho foi utilizado o modelo estatístico linear misto por meio de máxima verossimilhança restrita((REML-Restricted Maximum Likelihood), e melhor predição linear não viciada (BLUP - Best Linear Unbiased Prediction), por se tratar da melhor ferramenta estatística para decompor as variâncias e melhor estimar os paramentos genéticos de experimentos florestais (RESENDE et al., 1996a e 1996b). O modelo linear misto foi utilizado, conforme Resende (2007), com a equação abaixo, onde " $y$ " representa o vetor de dados fenotípicos, " $r$ " é o vetor dos efeitos de repetição (assumidos como fixos) somados à média geral, "a" é o vetor dos efeitos genéticos aditivos individuais (assumidos como aleatórios), " $\mathrm{p}$ " é o vetor dos efeitos de parcela (assumidos como aleatórios) e "e" representa o vetor de erros ou resíduos (aleatórios). O coeficiente " $\beta$ " refere-se à regressão associada a covariável índice de falhas, e as letras maiúsculas representam as matrizes de incidência para os referidos efeitos.

$$
y=X r+\beta C o v+Z a+W p+e
$$

Os efeitos dos modelos foram testados cientificamente pelo Teste da Razão de Verossimilhança (LRT), ou seja, pela diferença das deviances dos modelos e teste qui-quadrado com grau de liberda- 
de igual a 1. Para correlação do ranking dos genitores foi utilizado a Correlação de Spearman, ou de postos, pois dados pareados não seguem a uma distribuição normal (DIAS; BARROS, 2009). Para correlação dos valores genéticos aditivos preditos foi utilizado coeficiente de correlação de Pearson e regressão linear com os cálculos da significância da regressão, erro padrão da estimativa e coeficiente de determinação.

Para a eficiência da seleção precoce dos genitores foram comparados os dez melhores genitores selecionados aos oito anos de idade com seus respectivos desempenhos aos quinze anos de idade. O desempenho do genitor selecionado de forma precoce foi avaliado em relação a melhor de qualquer das três testemunhas de polinização aberta. Para esta comparação estatística dos valores genéticos aditivos dos genitores, e definição de diferença significativa ou não, foi adotado o intervalo de confiança a $5 \%$ de probabilidade conforme Cumming et al. (2007) utilizando o desvio padrão obtido para o modelo estatístico completo. Os dez melhores genitores selecionados aos oito anos foram considerados aprovados aos quinze anos quando apresentaram o limite inferior do intervalo de confiança superior ao limite superior do intervalo de confiança da melhor testemunha de polinização aberta. Com base neste critério o ganho genético alcançado com a seleção aos quinze anos, fruto da seleção precoce aos oito anos, foi estimado por meio da equação:

$$
\text { Ganho }=\left\{\left[\left(\frac{\Sigma \text { Vaa }}{\mathrm{nfa}}\right)+\text { média geral }\right] \cdot\left(\frac{\mathrm{nfa}}{10}\right)\right\}+\left\{\left[\frac{10-\mathrm{nfa}}{10}\right] \cdot \text { média testemunha }\right\}
$$

Na equação acima "Ganho" representa a média aos quinze anos fruto da seleção aos oito anos dos dez melhores genitores, " $\Sigma \mathrm{Vaa}$ " representa a soma do valor genético aditivo dos genitores aprovados aos quinze anos, "nfa" é o número das progênies ou genitores aprovados aos quinze anos, "média geral" corresponde à média geral do ensaio e "média testemunha" representa a média da melhor de qualquer das três testemunhas de polinização aberta utilizada no ensaio. A equação visa ponderar a média operacional pela quantidade de progênies aprovadas levando em conta que as dez progênies foram plantadas operacionalmente de forma igualitárias, ou seja, mescla de sementes, e considerando que as progênies não aprovadas tiveram a mesma média que a melhor testemunha de polinização aberta (semente disponível sem necessidade de investimento em programa de melhoramento).

Para avaliação da seleção precoce dos melhores indivíduos também foi adotado o intervalo de confiança a 5\% de probabilidade utilizando o desvio padrão obtido para o modelo estatístico completo, adotando se o critério de seleção dos 30 melhores indivíduos do teste de progênie, porém foram realizadas as estimativas com cinco cenários distintos para este pomar de segunda geração: (i) "Tardia. 30 ind." representa o pomar clonal de segunda geração implantado de forma tardia com a seleção dos 30 melhores indivíduos aos quinze anos de idade sem restrição de quantidade de indivíduos por família; (ii) "Precoce. 30 ind" representa a média obtida aos quinze anos com a seleção aos oito anos dos 30 melhores indivíduos sem restrição de quantidade de indivíduos por família, ou seja, o resultado da média aos quinzes anos do pomar clonal de segunda geração implantado de forma precoce sem nenhuma preocupação com tamanho efetivo populacional; (iii) "Tardia 3/fam. 30 ind." representa a média do resultado obtido com a seleção dos 30 melhores indivíduos aos quinze anos de idade com restrição de máximo três indivíduos por família para evitar uma redução drástica no tamanho efetivo populacional; (iv) "Precoce $3 /$ fam. $\underline{x}$ ind" representa um pomar clonal de segunda geração implantado de forma precoce com todos os indivíduos selecionados aos oito anos e posteriormente, com a avaliação aos quinze anos, retirado todos os indivíduos que não foram selecionados na idade final, sendo ambas as seleções com restrição três indivíduos por família; e por fim (v) "Precoce 3/fam, 30 ind." representa o pomar clonal de segunda geração implantado de forma precoce apenas com a seleção dos 30 melhores indivíduos selecionados aos oito anos de idade com restrição de máximo três indivíduos por família à média geral do ensaio e "média testemunha" representa a média da melhor de qualquer das três testemunhas de polinização aberta utilizada no ensaio. A equação visa ponderar a média operacional pela quantidade de progênies aprovadas levando em conta que as dez progênies foram plantadas operacionalmente de forma igualitárias, ou seja, mescla de sementes, e considerando que as progênies não aprovadas tiveram a mesma média que a melhor testemunha de polinização aberta (semente disponível sem necessidade de investimento em programa de melhoramento). Para avaliação da seleção precoce dos melhores indivíduos também foi adotado o intervalo de confiança a 5\% de probabilidade utili- 
zando o desvio padrão obtido para o modelo estatístico completo, adotando se o critério de seleção dos 30 melhores indivíduos do teste de progênie, porém foram realizadas as estimativas com cinco cenários distintos para este pomar de segunda geração: (i) "Tardia. 30 ind." representa o pomar clonal de segunda geração implantado de forma tardia com a seleção dos 30 melhores indivíduos aos quinze anos de idade sem restrição de quantidade de indivíduos por família; (ii) "Precoce. 30 ind" representa a média obtida aos quinze anos com a seleção aos oito anos dos 30 melhores indivíduos sem restrição de quantidade de indivíduos por família, ou seja, o resultado da média aos quinzes anos do pomar clonal de segunda geração implantado de forma precoce sem nenhuma preocupação com tamanho efetivo populacional; (iii) "Tardia 3/fam. 30 ind." representa a média do resultado obtido com a seleção dos 30 melhores indivíduos aos quinze anos de idade com restrição de máximo três indivíduos por família para evitar uma redução drástica no tamanho efetivo populacional; (iv) "Precoce 3/fam. $\underline{x}$ ind" representa um pomar clonal de segunda geração implantado de forma precoce com todos os indivíduos selecionados aos oito anos e posteriormente, com a avaliação aos quinze anos, retirado todos os indivíduos que não foram selecionados na idade final, sendo ambas as seleções com restrição três indivíduos por família; e por fim (v) "Precoce 3/fam, 30 ind." representa o pomar clonal de segunda geração implantado de forma precoce apenas com a seleção dos 30 melhores indivíduos selecionados aos oito anos de idade com restrição de máximo três indivíduos por família.

Para estimar o tamanho efetivo populacional foi utilizado a equação descrita por Resende (2007) e Pires et al. (2011) para progênies de meios-irmãos, considerando as matrizes não aparentadas,

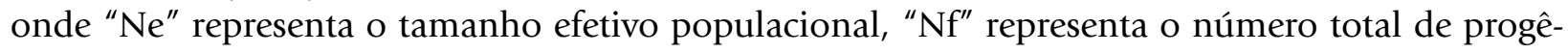
nies selecionadas, " $k f^{\text {" }}$ representa o número médio de indivíduos selecionados por família e " $\sigma^{2}$ " corresponde a variância do número de indivíduos selecionados por família.

$$
N e=\frac{4 \cdot N f \cdot k f}{k f+3+\left(\frac{\sigma_{k f}^{2}}{k f}\right)}
$$

\section{RESULTADOS E DISCUSSÃO}

O crescimento médio para a variável volume médio do fuste foi similar com 0,57 e 0,51 metros cúbicos sólidos com casca $\left(\mathrm{m}^{3} \mathrm{scc}\right)$ em Campo do Tenente e Morungava, respectivamente, possivelmente por terem mesmo clima e fitogeografia, e foi observado praticamente metade do crescimento para o ensaio Mocambo com $0,26 \mathrm{~m}^{3} \mathrm{ssc}$.

A diferença entre Campo do Tenente em relação a Morungava pode ser explicada pelo maior volume de precipitação média para Campo do Tenente, visto que a ordem do solo e profundidade serem similares. Como era esperado, as correlações fenotípicas para a mesma idade em cada local foram elevadas apenas entre a variável DAP e volume, sendo todas superiores a 0,96. Devido a esta elevada correlação do DAP com o volume estimado se optou por estimar os parâmetros genéticos e realizar os estudos com a variável DAP, pois se trata de uma medição direta com baixo nível de erro.

Para todos os locais e idades o coeficiente de determinação e consequentemente o componente de variância do efeito da progênie foi significativo a 1\%, com exceção do ensaio Mocambo aos quinze anos com 5\% de significância, sendo permitido desta forma a predição dos valores genéticos com este termo no modelo. O menor efeito da progênie no ensaio Mocambo aos quinze anos pode ser explicado pelo menor crescimento que o ambiente proporcionou a este material genético testado, pois como citado anteriormente, a seleção dos genitores das progênies de meios-irmãos ocorreu em Campo do Tenente com fitogeografia e clima muito distintos (Tabela 2). Nos três locais de estudo os efeitos da parcela não foram significativos aos oito anos de idade, porém foram altamente significativos no final da rotação, provavelmente pela maior competição das árvores adultas quando no fechamento do dossel do ensaio e maiores incrementos anuais de crescimento. Isto reforça a necessidade de correção das falhas das árvores vizinhas conforme citado anteriormente. $\mathrm{O}$ efeito fixo bloco não foi significativo na idade de rotação em nenhum dos ambientes, basicamente pelo crescimento desta espécie não ser tão sensível a variações pequenas no microambiente físico. 
Tabela 2. Análise de deviance com os componentes da variância, componentes de determinação e o teste da razão de verossimilhança de cada efeito, das análises separadas para cada local, para variável diâmetro à altura do peito (DAP cm).

Table 2. Deviance analysis with the components of the variance, determination components and the likelihood ratio test of each effect, from separated analyzes for each site, to the variable diameter at breast height $(\mathrm{DBH} \mathrm{cm})$.

\begin{tabular}{|c|c|c|c|c|c|c|}
\hline Local & $\begin{array}{l}\text { Idade } \\
\text { (Anos) }\end{array}$ & Efeito & Deviance & $\begin{array}{c}\text { Teste da Razão de } \\
\text { Verossimilhança (LRT) }\end{array}$ & $\begin{array}{l}\text { Compotentes da } \\
\text { Variância }\end{array}$ & $\begin{array}{l}\text { Coeficiente de } \\
\text { Determinação }\end{array}$ \\
\hline \multirow{10}{*}{$\begin{array}{l}\text { Campo } \\
\text { do Tenente }\end{array}$} & \multirow{5}{*}{8} & Progênie & $8.869,95$ & $27,73^{* *}$ & 2,591430 ** & $h^{2} a=0,257280^{* *}$ \\
\hline & & Parcela & $8.839,87$ & $-2,35^{\text {ns }}$ & $0,034675^{\mathrm{ns}}$ & $c^{2}$ parc $=0,003443^{n s}$ \\
\hline & & Resíduo & - & - & 7,446304 & $c^{2}$ res $=0,739277$ \\
\hline & & Modelo & $8.842,22$ & - & - & - \\
\hline & & Bloco & & teste $\mathrm{F}=0,162255^{*}$ & QM ef $=1,2082$ & \\
\hline & \multirow{5}{*}{15} & Progênie & $11.251,47$ & $-171,28^{* *}$ & $3,369405^{\star *}$ & $h^{2} a=0,18587^{* *}$ \\
\hline & & Parcela & $11.414,59$ & $-8,16^{* *}$ & $0,071792^{* *}$ & $c^{2}$ parc $=0,003960^{\star *}$ \\
\hline & & Resíduo & - & - & 14,68669 & $c^{2}$ res $=0,81017$ \\
\hline & & Modelo & $11.422,75$ & - & - & - \\
\hline & & Bloco & & teste $F=0,367442 \mathrm{~ns}$ & QM ef $=5,3965$ & \\
\hline \multirow{10}{*}{ Morungava } & \multirow{5}{*}{8} & Progênie & $10.417,95$ & $-62,61^{* *}$ & $2,232544^{* *}$ & $h^{2} a=0,166570^{\star *}$ \\
\hline & & Parcela & $10.479,40$ & $-1,16^{\mathrm{ns}}$ & $0,043535^{\text {ns }}$ & $c^{2}$ parc $=0,003248^{\text {ns }}$ \\
\hline & & Resíduo & - & - & 11,126995 & $c^{2}$ res $=0,830182$ \\
\hline & & Modelo & $10.480,56$ & - & - & - \\
\hline & & Bloco & & teste $F=0,10052^{* *}$ & $\mathrm{QM}$ ef $=1,1185$ & \\
\hline & \multirow{5}{*}{15} & Progênie & $12.380,49$ & $-153,54^{* \star}$ & $2,442819^{* *}$ & $\mathrm{~h}^{2} \mathrm{a}=0,130978^{* *}$ \\
\hline & & Parcela & $12.416,19$ & $-117,84^{* *}$ & $0,681223^{* *}$ & $c^{2}$ parc $=0,036525^{* *}$ \\
\hline & & Resíduo & - & - & 15,526585 & $c^{2}$ res $=0,832497$ \\
\hline & & Modelo & $12.534,03$ & - & - & - \\
\hline & & Bloco & & teste $F=0,246036^{\text {ns }}$ & QM ef $=3,8201$ & \\
\hline \multirow{10}{*}{ Mocambo } & \multirow{5}{*}{8} & Progênie & $8.871,30$ & $19,51^{* *}$ & $0,720222^{* *}$ & $h^{2} a=0,094382^{* *}$ \\
\hline & & Parcela & $8.849,18$ & $-2,61^{\text {ns }}$ & $0,039757^{\text {ns }}$ & $c^{2}$ parc $=0,00521^{\mathrm{ns}}$ \\
\hline & & Resíduo & - & - & 6,870909 & $c^{2}$ res $=0,900408$ \\
\hline & & Modelo & $8.851,79$ & - & - & - \\
\hline & & Bloco & & teste $F=1,713427^{\mathrm{ns}}$ & QM ef $=11,7728$ & \\
\hline & \multirow{5}{*}{15} & Progênie & $10.586,87$ & $4,84^{*}$ & $0,979058^{*}$ & $\mathrm{~h}^{2} \mathrm{a}=0,076782^{*}$ \\
\hline & & Parcela & $10.577,23$ & $-4,80^{*}$ & $0,062892^{*}$ & $c^{2}$ parc $=0,004932^{*}$ \\
\hline & & Resíduo & - & - & 11,709171 & $c^{2}$ res $=0,918286$ \\
\hline & & Modelo & $10.582,03$ & - & - & - \\
\hline & & Bloco & & teste $F=0,837412^{\mathrm{ns}}$ & $\mathrm{QM}$ ef $=9,8054$ & \\
\hline
\end{tabular}

Os valores com o símbolo ** e * representam estatisticamente os valores onde foram encontradas diferenças significativas a $5 \%$ e I\% de probabilidade, respectivamente. Os valores com o símbolo ns representam os valores sem efeito significativo. Efeito fixo= ef. Fonte: Do autor.

As herdabilidades variaram de 0,08 a 0,26 e diminuíram em todos os locais entre as idades de oito anos e quinze anos, consequentemente também diminuiu a acurácia entre as duas avaliações, possivelmente devido ao efeito ambiental de competição entre plantas que se expressa mais com aumento da idade. As herdabilidades foram relacionadas diretamente ao ambiente, onde Campo do Tenente, caracterizado como melhor ambiente com maior volume médio individual, apresentou as maiores herdabilidades, em ambas as idades, seguidos de Morungava e Mocambo, com menor herdabilidade, acurácia e crescimento volumétrico. A variância residual apresentou baixa amplitude entre os locais para uma mesma idade, sendo a maior amplitude observada de 4,26 entre Morungava e Mocambo na idade de oito anos (Tabela 3).

Para Pinus taeda L vários estudos indicam herdabilidades de 0,18 a 0,37 para altura das árvores, e 0,14 para diâmetro e volume das árvores (BALOCCHI et al., 1993; PAUL et al., 1997 citado por DUDA, 2003). No Brasil, estudos dos pesquisadores Paludzyszyn Filho et al. (2002), Duda (2003) e Martinez et al. (2012) realizados no Paraná, Santa Catarina e Sul de São Paulo, com progênies de polinização aberta, encontraram herdabilidades no sentido restrito variando de 0,18 a 0,46 para diâmetro das árvores, porém ambos os estudos as análises foram realizadas em idades precoces com idade máxima de oito anos. 
Tabela 3. Análise de máxima verossimilhança restrita com os componentes da variância, componentes de determinação, acurácia e coeficientes de variação, das análises separadas para cada local, para variável diâmetro a altura do peito (DAP $\mathrm{cm}$ ).

Table 3. Restricted maximum likelihood analysis with components of variance, components of determination, accuracy and coefficients of variation, from separated analyzes for each site, to the variable diameter at breast height $(\mathrm{DBH} \mathrm{cm})$.

\begin{tabular}{|c|c|c|c|c|c|c|}
\hline \multirow{3}{*}{$\begin{array}{l}\text { Componentes } \\
\text { de Variância } \\
\text { (REML Individual) }\end{array}$} & \multicolumn{2}{|c|}{ Campo do Tenente } & \multicolumn{2}{|c|}{ Morungava } & \multicolumn{2}{|c|}{ Mocambo } \\
\hline & 8 anos & 15 anos & 8 anos & 15 anos & 8 anos & 15 anos \\
\hline & 1 & 2 & 3 & 4 & 5 & 6 \\
\hline $\mathrm{Va}$ & $2,59143^{* *}$ & $3,36941^{* *}$ & $2,23254^{* *}$ & $2,44282^{* *}$ & $0,72022^{* *}$ & $0,97906^{*}$ \\
\hline Vparc & $0,03468^{\text {ns }}$ & $0,07179^{* *}$ & $0,04354^{\mathrm{ns}}$ & $0,68122^{* *}$ & $0,03976^{\text {ns }}$ & $0,06289^{*}$ \\
\hline Ve & 7,45 & 14,69 & 11,13 & 15,53 & 6,87 & 11,71 \\
\hline$V f$ & 10,07 & 18,13 & 13,40 & 18,65 & 7,63 & 12,75 \\
\hline \multirow{2}{*}{$\mathrm{h} 2 \mathrm{a}$} & $0,25728^{* *}$ & $0,18587^{* *}$ & $0,16657^{* *}$ & $0,13098^{* *}$ & $0,09438^{* *}$ & $0,07678^{*}$ \\
\hline & $+-0,0574$ & $+-0,0532$ & $+-0,0441$ & $+-0,0423$ & $+-0,0332$ & $+-0,0306$ \\
\hline h2aj & 0,2582 & 0,1866 & 0,1671 & 0,1359 & 0,0949 & 0,0772 \\
\hline c2parc & $0,003443^{\text {ns }}$ & $0,00396^{* *}$ & $0,00325^{\mathrm{ns}}$ & $0,03653^{* *}$ & $0,00521^{\mathrm{ns}}$ & $0,0049^{*}$ \\
\hline $\mathrm{h} 2 \mathrm{mp}$ & 0,7304 & 0,6572 & 0,6317 & 0,5405 & 0,4862 & 0,4342 \\
\hline Acprog & 0,8547 & 0,8107 & 0,7948 & 0,7352 & 0,6973 & 0,6589 \\
\hline h2ad & 0,2070 & 0,1468 & 0,1308 & 0,1055 & 0,0729 & 0,0590 \\
\hline CVgi\% & 7,84 & 7,17 & 7,23 & 6,55 & 5,25 & 5,12 \\
\hline CVgp\% & 3,92 & 3,59 & 3,61 & 3,27 & 2,62 & 2,56 \\
\hline CVe\% & 6,74 & 7,32 & 7,81 & 8,54 & 7,63 & 8,26 \\
\hline$C V r$ & 0,58 & 0,49 & 0,46 & 0,38 & 0,34 & 0,31 \\
\hline PEV & 0,1746 & 0,2887 & 0,2056 & 0,2806 & 0,0925 & 0,1385 \\
\hline SEP & 0,4179 & 0,5373 & 0,4534 & 0,5297 & 0,3041 & 0,3721 \\
\hline $\begin{array}{l}\text { Média geral do experi- } \\
\text { mento }\end{array}$ & 20,5 & 25,6 & 20,7 & 23,9 & 16,2 & 19,3 \\
\hline Beta & 0,9178 & 1,0280 & 1,1926 & 1,1197 & 0,7681 & 0,8904 \\
\hline Média Cov & 0,1210 & 0,9944 & 0,1235 & 0,9011 & 0,1157 & 0,3415 \\
\hline
\end{tabular}

$\mathrm{Va}=$ variância genética aditiva. $\mathrm{Vparc}=$ variância ambiental entre parcelas. $\mathrm{Ve}=$ variância residual (ambiental + não aditiva). $\mathrm{Vf}=$ variância fenotípica individual. $\mathrm{h} 2 \mathrm{a}=$ herdabilidade individual no sentido restrito, ou seja, dos efeitos aditivos. $\mathrm{h} 2 \mathrm{aj}=\mathrm{herdabilidade}$ individual no sentido restrito, ajustada para os efeitos de parcela. $c 2$ parc $=$ coeficiente de determinação dos efeitos de parcela. $h 2 \mathrm{mp}=\mathrm{herdabilidade}$ da média de progênies, assumindo sobrevivência completa. Acprog = acurácia da seleção de progênies, assumindo sobrevivência completa. $\mathrm{h} 2 \mathrm{ad}=\mathrm{herdabilidade}$ aditiva dentro de parcela. $\mathrm{CVgi} \%=$ coeficiente de variação genética aditiva individual. $\mathrm{CVgp} \%=$ coeficiente de variação genotípica entre progênies. $\mathrm{CVe} \%=$ coeficiente de variação residual. $\mathrm{CVr}=$ coeficiente de variação relativa. $\mathrm{PEV}=$ variância do erro de predição dos valores genotípicos de progênie, assumindo sobrevivência completa. SEP = desvio padrão do valor genotípico predito de progênie, assumindo sobrevivência completa. Beta $=$ coeficiente de regressão associado à covariável. Média Cov= Média da covariável. Os valores com o símbolo ** e $*$ representam estatisticamente os valores onde não foram encontradas diferenças significativas a $5 \%$ e $1 \%$ de probabilidade, respectivamente.

O desvio padrão do valor genotípico predito de progênies, assumindo sobrevivência completa, foi baixo com percentual de aproximadamente 2,0\% em relação à média geral do experimento em todos os locais e idades. A média da covariável índice de falhas foi pequena na idade precoce em todos os locais, pois todos os três locais apresentaram sobrevivência média geral de $98 \%$, porém a média do índice de falhas aumentou de forma considerável na idade da rotação final. Embora a sobrevivência média geral na rotação final de quinze anos de Campo do Tenente e Mocambo serem similares, com aproximadamente 82 e $84 \%$, e Morungava com 94\% de sobrevivência, esta média do índice de falhas apresentou comportamento inverso ao maior potencial de crescimento, ou seja, em Campo do Tenente o maior crescimento proporcionou maior mortalidade tardia de árvores de forma dispersa e não agrupada, como ocorreu no ensaio Mocambo. Este comportamento da sobrevivência geral ser similar, porém o índice de falhas ser tão distinto, reforça a hipótese de se corrigir o efeito do menor número de árvores vizinhas em todos os tratamentos via covariável conforme recomendação de Pires et al. (2011).

Nos três locais do estudo as correlações de ordenamento foram elevadas e superiores a 0,85 com $1 \%$ de significância, permitindo inferir que para o ordenamento geral dos genitores a seleção precoce foi muito eficiente em todos os locais. As três testemunhas de polinização aberta utilizadas no estudo foram estatisticamente iguais com exceção de Campo do Tenente na idade precoce, onde a testemunha com sementes de Área de Produção de Sementes (72) do município de Itapeva, São Paulo, apresentou menor crescimento (Tabela 4). Desta forma, na idade de rotação todas as sementes de polinização aberta utilizadas como testemunha apresentaram igualdade estatística 
mediante o rigor estatístico utilizado. Analisando os dez melhores genitores, foi possível observar que sete, seis e cinco dos dez melhores foram coincidentes em Campo do Tenente, Morungava e Mocambo, respectivamente.

Tabela 4. Valores genéticos aditivos das progênies nas idades de 8 e 15 anos e as respectivas correlações de Spearman para cada local. Estão apresentados também as progênies que apresentaram valores genético aditivo estatisticamente superior ao valor da melhor testemunha de polinização aberta (tratamentos 71 a 73). Os valores genéticos aditivos reforçados em cinza representam os 10 maiores valores para cada idade e local.

Table 4. Genetic additive values of the progenies at ages 8 and 15 years and the respective Spearman correlations for each site. Also, progenies that have presented genetic additive values statistically higher than the value of the best control of open pollination (treatments 71 to 73 ). The bold additive genetic values represent the 10 highest values for each age and site.

\begin{tabular}{|c|c|c|c|c|c|c|c|c|c|c|c|c|}
\hline \multirow{3}{*}{$\begin{array}{l}\text { Progênies } \\
(1 \text { a } 70) \\
\text { Testemunhas }\end{array}$} & \multicolumn{4}{|c|}{ Campo do Tenente } & \multicolumn{4}{|c|}{ Morungava } & \multicolumn{4}{|c|}{ Mocambo } \\
\hline & \multicolumn{2}{|c|}{$\begin{array}{c}8 \text { anos } \\
\text { Spearman }\end{array}$} & \multicolumn{2}{|c|}{$\begin{array}{c}15 \text { anos } \\
0,87 \text { ** }\end{array}$} & \multicolumn{2}{|c|}{$\begin{array}{c}8 \text { anos } \\
\text { Spearman }\end{array}$} & \multicolumn{2}{|c|}{$\begin{array}{c}15 \text { anos } \\
0,82 \text { ** }\end{array}$} & \multicolumn{2}{|c|}{$\begin{array}{c}8 \text { anos } \\
\text { Spearman }\end{array}$} & \multicolumn{2}{|c|}{$\begin{array}{c}15 \text { anos } \\
0,85^{* *}\end{array}$} \\
\hline & SEP & 0,4179 & SEP & 0,5373 & SEP & 0,4534 & SEP & 0,5297 & SEP & 0,3041 & SEP & 0,3721 \\
\hline (71 a 74 ) & $\begin{array}{c}\text { IC } 5 \% \\
\text { Vga }\end{array}$ & $\begin{array}{c}0,8191 \\
>\text { test }\end{array}$ & $\begin{array}{l}\text { IC } 5 \% \\
\text { Vga }\end{array}$ & $\begin{array}{c}1,0532 \\
>\text { test }\end{array}$ & $\begin{array}{l}\text { IC } 5 \% \\
\text { Vga }\end{array}$ & $\begin{array}{c}0,8887 \\
>\text { test }\end{array}$ & $\begin{array}{l}\text { IC } 5 \% \\
\text { Vga }\end{array}$ & $\begin{array}{c}1,0382 \\
>\text { test }\end{array}$ & $\begin{array}{l}\text { IC } 5 \% \\
\text { Vga }\end{array}$ & $\begin{array}{c}0,5961 \\
>\text { test }\end{array}$ & $\begin{array}{l}\text { IC } 5 \% \\
\text { Vga }\end{array}$ & $\begin{array}{c}0,7294 \\
>\text { test }\end{array}$ \\
\hline 1 & 20,1 & & 24,7 & & 21,8 & & 23,4 & & 16,3 & & 19,6 & \\
\hline 2 & 21,0 & $x$ & 26,4 & & 21,5 & & 23,3 & & 16,8 & & 19,6 & \\
\hline 3 & 19,2 & & 23,8 & & 21,0 & & 21,9 & & 16,2 & & 19,0 & \\
\hline 4 & 20,0 & & 24,7 & & 21,2 & & 23,6 & & 15,8 & & 19,3 & \\
\hline 5 & 19,9 & & 25,4 & & 21,2 & & 24,6 & & 15,3 & & 19,1 & \\
\hline 6 & 23,0 & $x$ & 27,8 & $x$ & 22,3 & & 24,4 & & 17,0 & & 20,3 & \\
\hline 7 & 21,3 & $x$ & 26,4 & & 21,8 & & 23,6 & & 16,3 & & 19,3 & \\
\hline 8 & 17,9 & & 22,5 & & 20,8 & & 21,7 & & 14,7 & & 17,6 & \\
\hline 9 & 17,8 & & 23,0 & & 21,0 & & 22,6 & & 16,5 & & 19,9 & \\
\hline 10 & 22,2 & $x$ & 27,6 & $x$ & 22,1 & & 25,4 & $x$ & 16,7 & & 19,4 & \\
\hline 11 & 20,3 & & 25,6 & & 21,3 & & 22,9 & & 16,1 & & 19,4 & \\
\hline 12 & 19,6 & & 24,9 & & 21,6 & & 24,7 & & 16,1 & & 19,4 & \\
\hline 13 & 22,4 & $x$ & 27,1 & $x$ & 21,9 & & 23,6 & & 16,2 & & 19,4 & \\
\hline 14 & 19,3 & & 25,1 & & 20,9 & & 22,2 & & 16,1 & & 18,7 & \\
\hline 15 & 20,2 & & 26,5 & & 21,7 & & 23,7 & & 16,0 & & 20,0 & \\
\hline 16 & 21,5 & $x$ & 27,1 & $x$ & 21,6 & & 24,6 & & 15,3 & & 18,4 & \\
\hline 17 & 21,2 & $x$ & 25,7 & & 22,5 & & 25,2 & $x$ & 16,3 & & 19,7 & \\
\hline 18 & 22,9 & $x$ & 27,7 & $x$ & 21,8 & & 24,3 & & 16,8 & & 20,2 & \\
\hline 19 & 20,4 & & 26,4 & & 21,3 & & 24,0 & & 16,1 & & 19,1 & \\
\hline 20 & & & & & 21,9 & & 24,1 & & 15,7 & & 18,9 & \\
\hline 21 & 18,6 & & 24,1 & & 21,6 & & 23,8 & & 16,4 & & 20,0 & \\
\hline 22 & 23,4 & $x$ & 29,7 & $x$ & 22,6 & & 26,2 & $x$ & 17,3 & & 20,6 & \\
\hline 23 & 20,9 & $x$ & 25,9 & & 21,2 & & 23,4 & & 15,8 & & 18,6 & \\
\hline 24 & 21,5 & $x$ & 26,1 & & 22,0 & & 25,0 & & 15,8 & & 18,6 & \\
\hline 25 & 22,1 & $x$ & 27,7 & $x$ & 22,4 & & 26,4 & $x$ & 17,2 & & 20,9 & \\
\hline 26 & 20,3 & & 25,3 & & 22,0 & & 24,9 & & 15,2 & & 18,3 & \\
\hline 27 & 21,0 & $x$ & 27,5 & $x$ & 21,2 & & 23,2 & & 15,7 & & 19,0 & \\
\hline 28 & 20,5 & & 24,9 & & 22,1 & & 24,9 & & 16,8 & & 19,5 & \\
\hline 29 & 20,1 & & 25,8 & & 21,4 & & 23,7 & & 15,9 & & 19,3 & \\
\hline 30 & 18,8 & & 23,8 & & 20,9 & & 23,1 & & 14,9 & & 18,6 & \\
\hline 31 & 21,1 & $x$ & 26,1 & & 21,5 & & 24,0 & & 16,8 & & 19,6 & \\
\hline 32 & 22,5 & $x$ & 27,5 & $x$ & 22,3 & & 25,7 & $x$ & 16,0 & & 19,3 & \\
\hline 33 & & & & & 21,7 & & 24,7 & & 16,5 & & 19,8 & \\
\hline 34 & 20,4 & & 24,7 & & 21,6 & & 24,7 & & 17,2 & & 20,3 & \\
\hline 35 & 19,7 & & 24,9 & & 21,3 & & 22,6 & & 16,9 & & 19,9 & \\
\hline 36 & 18,7 & & 23,1 & & 20,7 & & 22,2 & & 16,7 & & 20,0 & \\
\hline 37 & 22,0 & $x$ & 27,2 & $x$ & 22,2 & & 24,4 & & 16,2 & & 19,2 & \\
\hline 39 & 20,1 & & 24,6 & & 21,4 & & 22,9 & & 15,2 & & 18,0 & \\
\hline 42 & & & & & 21,9 & & 25,6 & $x$ & 16,2 & & 19,2 & \\
\hline 43 & 21,5 & $x$ & 26,7 & & 22,0 & & 23,2 & & 15,8 & & 18,9 & \\
\hline 44 & 22,8 & $x$ & 27,4 & $x$ & 22,4 & & 26,0 & $x$ & 16,6 & & 19,4 & \\
\hline 45 & 19,5 & & 24,3 & & 22,3 & & 24,8 & & 16,2 & & 19,2 & \\
\hline 46 & 19,8 & & 24,5 & & 21,1 & & 23,6 & & 15,9 & & 18,9 & \\
\hline
\end{tabular}


Tabela 4 - Continuação. Valores genéticos aditivos das progênies nas idades de 8 e 15 anos e as respectivas correlações de Spearman para cada local. Estão apresentados também as progênies que apresentaram valores genético aditivo estatisticamente superior ao valor da melhor testemunha de polinização aberta (tratamentos 71 a 73). Os valores genéticos aditivos reforçados em cinza representam os 10 maiores valores para cada idade e local.

Table 4 - Continuation. Genetic additive values of the progenies at ages 8 and 15 years and the respective Spearman correlations for each site. Also, progenies that have presented genetic additive values statistically higher than the value of the best control of open pollination (treatments 71 to 73). The bold additive genetic values represent the 10 highest values for each age and site.

\begin{tabular}{|c|c|c|c|c|c|c|c|c|c|c|c|c|}
\hline \multirow{3}{*}{$\begin{array}{l}\text { Progênies } \\
(1 \text { a } 70) \\
\text { Testemunhas }\end{array}$} & \multicolumn{4}{|c|}{ Campo do Tenente } & \multicolumn{4}{|c|}{ Morungava } & \multicolumn{4}{|c|}{ Mocambo } \\
\hline & \multicolumn{2}{|c|}{$\begin{array}{c}8 \text { anos } \\
\text { Spearman }\end{array}$} & \multicolumn{2}{|c|}{$\begin{array}{c}15 \text { anos } \\
0,87^{* *}\end{array}$} & \multicolumn{2}{|c|}{$\begin{array}{c}8 \text { anos } \\
\text { Spearman }\end{array}$} & \multicolumn{2}{|c|}{$\begin{array}{c}15 \text { anos } \\
0,82 \text { ** }\end{array}$} & \multicolumn{2}{|c|}{$\begin{array}{c}8 \text { anos } \\
\text { Spearman }\end{array}$} & \multicolumn{2}{|c|}{$\begin{array}{c}15 \text { anos } \\
0,85 \text { ** }\end{array}$} \\
\hline & SEP & 0,4179 & SEP & 0,5373 & SEP & 0,4534 & SEP & 0,5297 & SEP & 0,3041 & SEP & 0,3721 \\
\hline (71 a 74$)$ & $\begin{array}{c}\text { IC } 5 \% \\
\text { Vga }\end{array}$ & $\begin{array}{c}0,8191 \\
\text { >test }\end{array}$ & $\begin{array}{l}\text { IC } 5 \% \\
\text { Vga }\end{array}$ & $\begin{array}{c}1,0532 \\
>\text { test }\end{array}$ & $\begin{array}{l}\text { IC } 5 \% \\
\text { Vga }\end{array}$ & $\begin{array}{c}0,8887 \\
\text { >test }\end{array}$ & $\begin{array}{l}\text { IC } 5 \% \\
\text { Vga }\end{array}$ & $\begin{array}{c}1,0382 \\
>\text { test }\end{array}$ & $\begin{array}{l}\text { IC } 5 \% \\
\text { Vga }\end{array}$ & $\begin{array}{c}0,5961 \\
>\text { test }\end{array}$ & $\begin{array}{l}\text { IC } 5 \% \\
\text { Vga }\end{array}$ & $\begin{array}{c}0,7294 \\
\text { >test }\end{array}$ \\
\hline 47 & 20,6 & & 24,7 & & 21,7 & & 23,8 & & 16,5 & & 19,6 & \\
\hline 48 & & & & & 21,2 & & 23,6 & & 16,3 & & 19,5 & \\
\hline 49 & 21,3 & $x$ & 26,0 & & 22,1 & & 24,0 & & 16,4 & & 19,5 & \\
\hline 50 & 20,7 & & 24,7 & & 22,2 & & 23,6 & & 16,2 & & 18,6 & \\
\hline 51 & 22,2 & $x$ & 27,0 & $x$ & 21,8 & & 24,3 & & 16,6 & & 19,5 & \\
\hline 52 & 20,8 & $x$ & 23,6 & & 22,1 & & 24,7 & & 16,9 & & 19,5 & \\
\hline 54 & 19,8 & & 24,3 & & 21,4 & & 22,6 & & 15,9 & & 19,3 & \\
\hline 55 & & & & & 21,0 & & 22,7 & & 15,9 & & 19,2 & \\
\hline 56 & 21,3 & $x$ & 26,3 & & 22,2 & & 25,4 & $x$ & 16,3 & & 19,1 & \\
\hline 57 & 21,8 & $x$ & 28,1 & $x$ & 22,0 & & 23,8 & & 16,3 & & 19,2 & \\
\hline 58 & 20,8 & $x$ & 25,7 & & 21,4 & & 23,3 & & 16,5 & & 19,9 & \\
\hline 59 & 18,8 & & 24,6 & & 21,1 & & 23,2 & & 16,5 & & 20,1 & \\
\hline 60 & 19,9 & & 23,9 & & 21,3 & & 22,9 & & 15,2 & & 17,9 & \\
\hline 61 & 21,1 & $x$ & 26,2 & & 21,4 & & 24,1 & & 16,8 & & 19,9 & \\
\hline 62 & 21,4 & $x$ & 25,8 & & 21,5 & & 22,8 & & 16,0 & & 19,1 & \\
\hline 63 & 21,4 & $x$ & 27,2 & $x$ & 22,2 & & 24,6 & & 16,8 & & 19,8 & \\
\hline 64 & 20,4 & & 25,0 & & 21,5 & & 24,1 & & 15,9 & & 19,4 & \\
\hline 65 & 18,8 & & 24,0 & & 20,7 & & 22,4 & & 14,6 & & 18,2 & \\
\hline 66 & 21,0 & $x$ & 25,6 & & 22,4 & & 24,6 & & 16,4 & & 19,6 & \\
\hline 67 & 18,6 & & 25,3 & & 20,7 & & 22,7 & & 16,3 & & 19,8 & \\
\hline 68 & & & & & 20,9 & & 22,4 & & 15,8 & & 19,4 & \\
\hline 69 & 20,7 & & 25,6 & & 21,7 & & 25,2 & $x$ & 16,5 & & 20,0 & \\
\hline 70 & 22,4 & $x$ & 26,7 & & 22,5 & & 25,2 & $x$ & 16,7 & & 20,2 & \\
\hline 71 & 19,1 & & 24,8 & & 20,8 & & 22,2 & & 15,4 & & 18,6 & \\
\hline 72 & 17,0 & & 23,7 & & 21,1 & & 23,0 & & 15,8 & & 18,6 & \\
\hline 73 & 18,4 & & 24,6 & & 21,0 & & 22,0 & & 16,6 & & 20,0 & \\
\hline 74 & 19,6 & & 24,7 & & 22,7 & & 25,0 & & 15,2 & & 18,7 & \\
\hline $\begin{array}{l}\text { No. de PA t } \\
\text { estadas }\end{array}$ & 60 & & 60 & & 66 & & 66 & & 66 & & 66 & \\
\hline $\begin{array}{l}\text { No. de PA } \\
\text { aprovadas }\end{array}$ & & 29 & & 14 & & 0 & & 10 & & 0 & & 0 \\
\hline
\end{tabular}

Ainda na Tabela 4 observa-se que para Campo do Tenente foi possível selecionar um maior número de progênies com superioridade estatística em relação a melhor testemunha de polinização aberta, sendo 29 progênies na idade de oito anos e 14 progênies na idade de quinze anos. Este decréscimo no número de progênies entre as idades avaliadas nos permite inferir que é necessária precaução na seleção em idades precoces, pois 15 progênies de meios-irmãos se tornaram iguais à testemunha mediante o aumento de idade do ensaio. Este comportamento do elevado número de progênies e também no decréscimo de progênies aprovados foi exclusivo de Campo do Tenente, possivelmente devido que a seleção das matrizes foi realizada neste local, e a procedência das sementes destas matrizes seja o município de Três Barras, estado de Santa Catarina, com fitogeografia e clima muito similares a Campo do Tenente. Para o ensaio de Morungava o comportamento do número de progênies aprovados foi o contrário de Campo do Tenente, onde aos oito anos nenhum genitor apresentou progênies de meios-irmãos superiores a testemunha, porém na idade de quinze anos dez genitores conseguiram se diferenciar com crescimento estatisticamente superior. No en- 
saio Mocambo, devido ao ambiente distinto dos demais ensaios, e também ambiente distinto do histórico da origem das matrizes, nenhuma progênie se apresentou maior que a testemunha para ambas as idades. Para este ambiente com fitogeografia Cerrado e clima Cfa não é recomendado as progênies desta população genética avaliada sendo necessária avaliação de novos germoplasmas. Na Figura 2 são apresentados os valores genéticos aditivos de todos os tratamentos para todos os locais com maior detalhe, pois são apresentados os intervalos de confiança de todos os tratamentos, complementando a análise e discussão da Tabela 4.

Os resultados das correlações lineares foram similares com as correlações de ordenamento, tendo Campo do Tenente apresentando correlação linear de Pearson de 0,87 e, conforme já citado, também 0,87 para correlação de Spearman, ambas as correlações com 1\% de significância. Os resultados para Morungava também foram exatamente os mesmos com 0,82 em ambas as correlações, e o ensaio da Mocambo com 0,86 e 0,85 para correlação linear e de ordem respectivamente, sendo para todas as correlações encontrado também 1\% de significância (Figura 3).

Pesquisadores como Gwaze et al. (2001) também comprovaram a eficiência da seleção precoce em relação a seleção tardia para os parâmetros genéticos de diâmetro a altura do peito, altura e densidade da madeira. Analisaram quatro ensaios genéticos de Pinus taeda L. localizados no estado de Arkansas, avaliados nas idades de 5, 10, 15, 20 e 25 anos. Os pesquisadores concluíram que a seleção nas idades jovens foi eficiente e a correlação genética entre as idades para o diâmetro a altura do peito foi maior que 0,89 entre as idades de 10 a 20 anos, permitindo recomendações genéticas, com excelente acurácia, com uma década de antecedência.

Outro estudo sob o tema de idade ótima de seleção precoce de Pinus taeda L. foi conduzido por (GWAZE et al., 1997) com quatro ensaios genéticos implantados em Zimbabwe. Os ensaios foram avaliados nas idades de 1,5, 9,5, 13,5 e 22,5 anos e, para a variável altura total, concluíram que a correlação genética entre as idades foi de 0,76 a 0,97 , sendo a correlação genética sempre melhor que a correlação fenotípica. Os pesquisadores concluíram também que, assumindo a floração do ensaio aos dez anos de idades, nesta idade o ganho anual da seleção precoce compensa esta estratégia de acelerar a recomendação.

Na Figura 4 estão os valores do ganho genético em DAP e eficiência da seleção na idade de quinze anos com a seleção nesta idade final (seleção tardia) e com a seleção na idade de oito anos (seleção precoce), para os três locais, com a seleção dos genitores testados e aprovados estatisticamente, com número máximo de genitores igual a dez. Foi possível observar que apenas em Campo do Tenente o ganho com a seleção precoce foi superior à melhor testemunha de polinização aberta mediante o rigor estatístico utilizado, pois apenas um genitor selecionado de forma precoce apresentou mesmo crescimento que a testemunha na idade de quinze anos. Desta forma, para Campo do Tenente, onde a seleção das matrizes e avaliação das progênies no mesmo ambiente os resultados concordam Paludzyszyn Filho et al. (2002) que analisaram a seleção genética de Pinus taeda L. em duas idades distintas em ensaios genéticos implantados no estado do Paraná, concluindo que os ganhos genéticos aditivos preditos foram similares para as duas idades estudadas, revelando alto potencial para a seleção precoce, e, conforme citado na introdução deste estudo, aguardar a idade tardia de seleção não supera o benefício de se obter oferta antecipada de sementes com a seleção precoce dos genitores do pomar clonal.

O pomar clonal de segunda geração poderá trazer ganhos genéticos comprovados para os ambientes de Campo do Tenente e Morungava, porem nenhum ganho genético para o ensaio Mocambo pela peculiaridade já citada anteriormente (Figura 5). Para os locais Campo do Tenente e Morungava, a nova média para os três cenários de seleção precoce foram iguais estatisticamente porém apresentaram grande diferença no tamanho efetivo populacional. Era esperado que a restrição de três indivíduos por família evitaria redução drástica no tamanho efetivo, porém, outra vantagem foi observada, pois não houve perdas na nova média com a adoção desta restrição, ou seja, altamente recomendável. Como a média foi estatisticamente similar nos três cenários, não é recomendável desbastar o pomar com a retirada dos indivíduos não selecionados na idade final de rotação, sendo recomendável selecionar os 30 melhores indivíduos com a restrição de três indivíduos por família e permanecer com os mesmos 30 indivíduos, pois isto levou um aumento no tamanho efetivo populacional da ordem de 3 progênies. Se fosse desbastado o pomar com base nos indivíduos selecionados na idade final de rotação, em Campo do Tenente teríamos a exclusão 
de seis indivíduos $(\mathrm{n}=24)$ e Morungava a exclusão de oito indivíduos $(\mathrm{n}=22)$, reduzindo o tamanho efetivo de 22,4 ( $n=30)$, valor igual em ambos os dois locais, para 19,4 e 18,9 em Campo do Tenente e Morungava respectivamente.

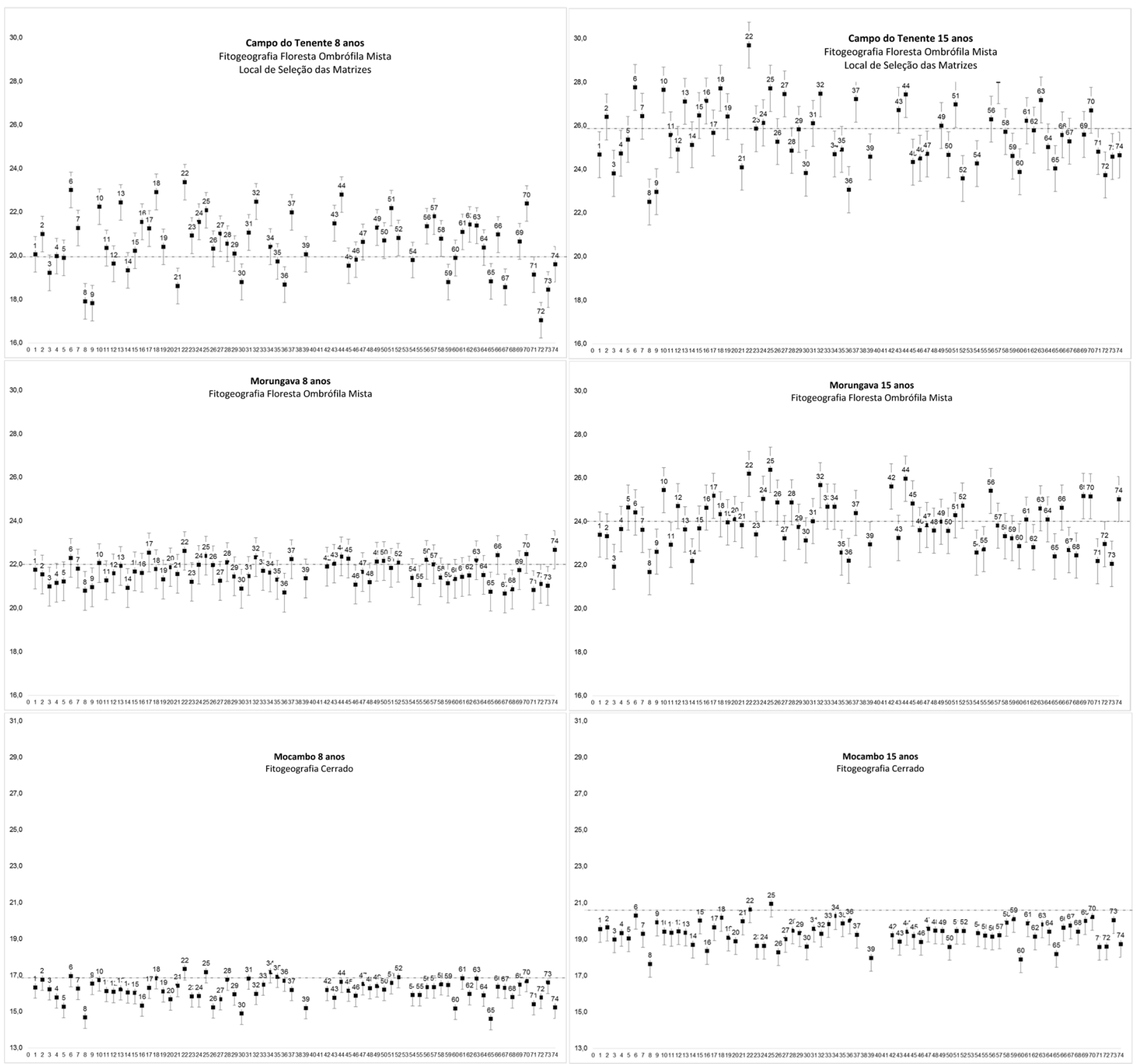

Figura 2. Valores genéticos aditivos das progênies e testemunhas para todos os locais nas idades de 8 e 15 anos com o intervalo de confiança a 5\%, onde o local Campo do Tenente foi o local de seleção das matrizes e está localizado na mesma fitogeografia de Morungava. O tracejado representa o limite superior da melhor testemunha de polinização aberta em cada local.

Figure 2. Genetic additive values of progenies and controls for all sites at ages 8 and 15 years with confidence interval of 5\%, where the site Campo do Tenente was the site of selection of the matrices and is located in the same phytogeography of Morungava. The dashed area represents the upper limit of the best open pollination control at each site. 


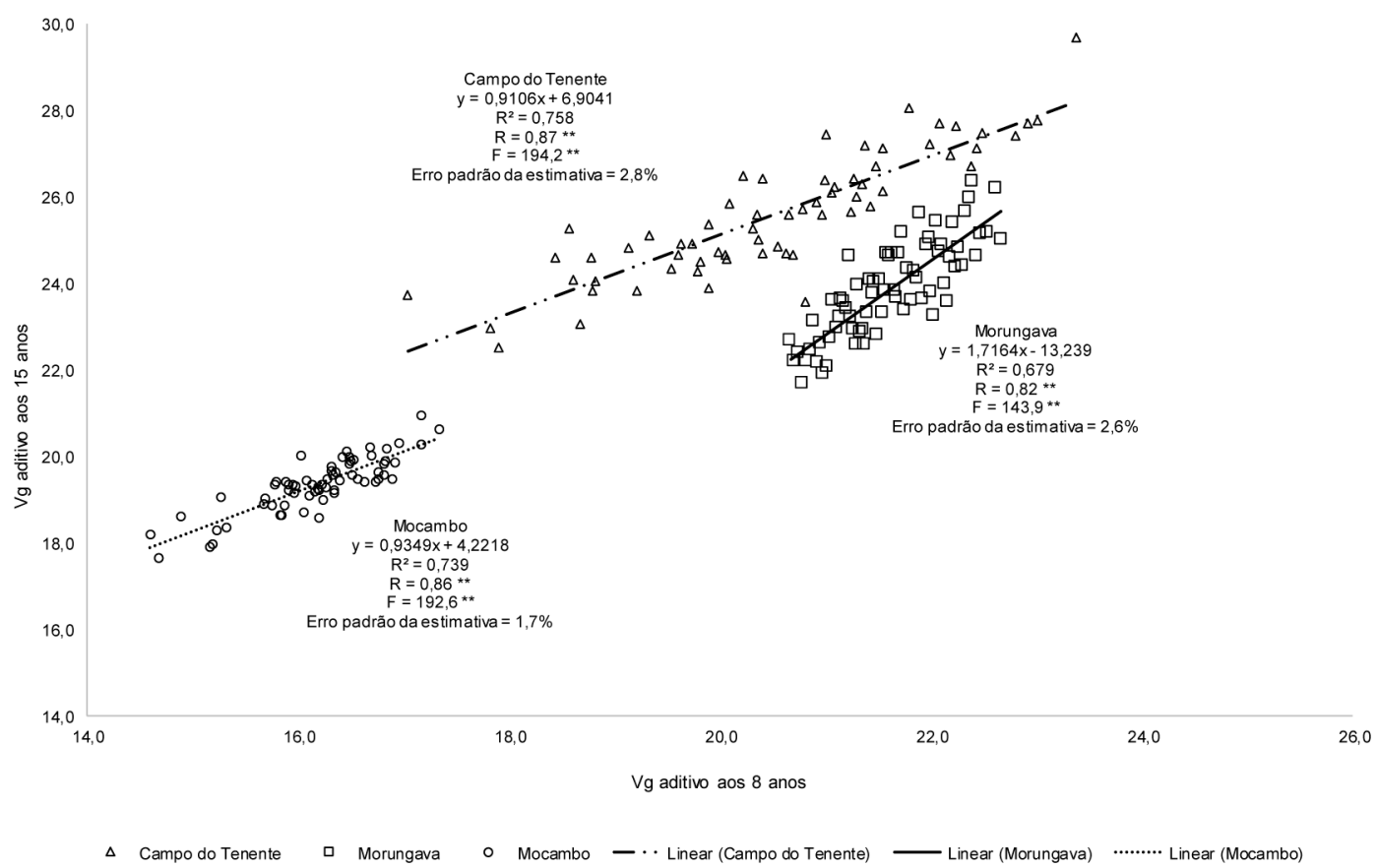

Figura 3. Regressões lineares e estatísticas relacionadas, bem como as correlações de Pearson dos valores genéticos aditivos em Campo do Tenente, Morungava e Mocambo entre as idades de 8 e 15 anos para cada local.

Figure 3. Linear regressions and related statistics, as well as Pearson's correlations of the additive genetic values in Campo do Tenente, Morungava and Mocambo between the ages of 8 and 15 years for each site.

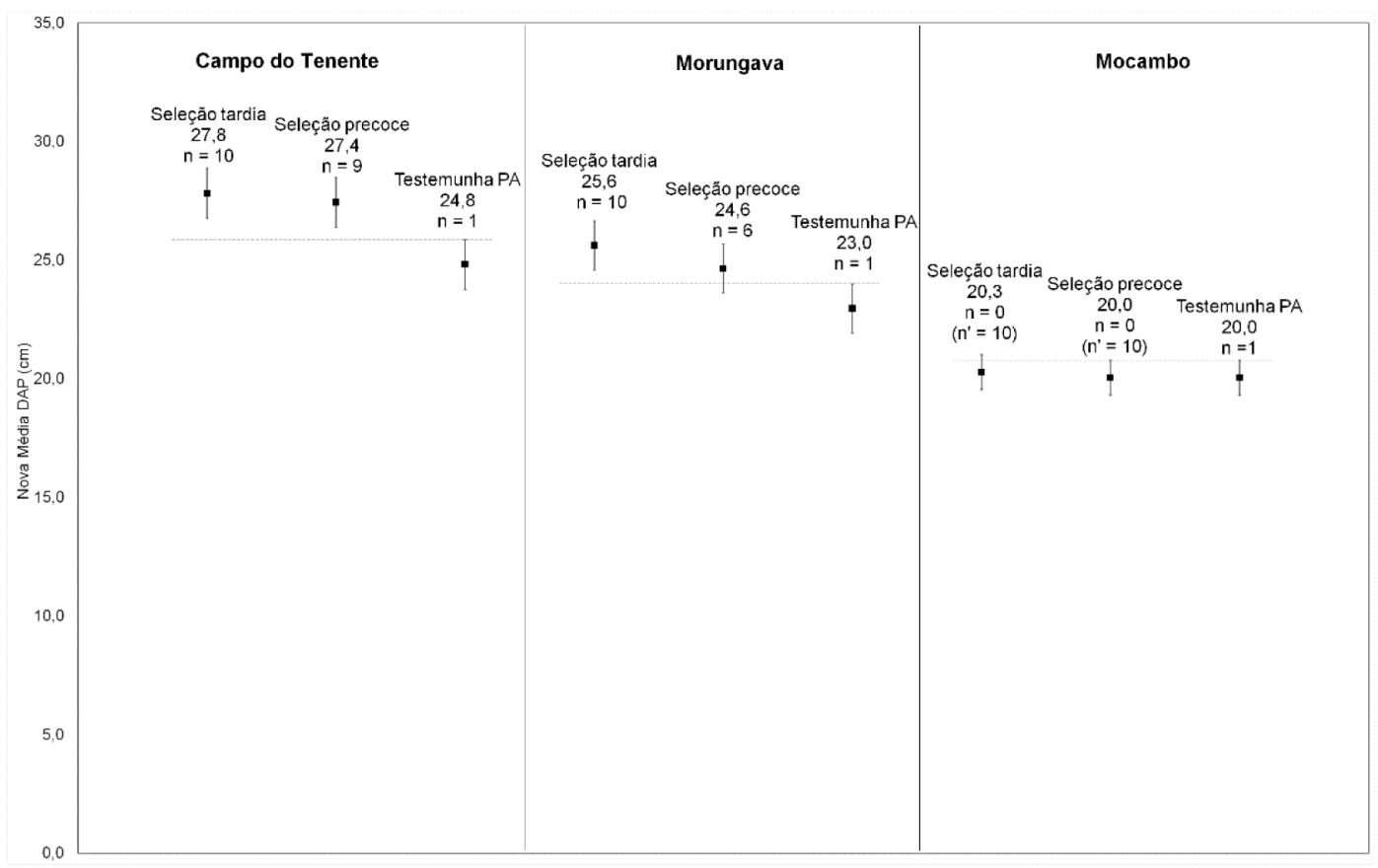

Figura 4. Valores do ganho genético dos genitores em DAP (cm) aos 15 anos com a seleção na idade de rotação (seleção tardia) e com a seleção na idade de 8 anos (seleção precoce), para os três locais, com a seleção dos genitores testados e aprovados estatisticamente, com n máximo igual a 10 . O n' representa a quantidade de genitores utilizados para a média quando nenhum genitor foi aprovado estatisticamente. 0 tracejado representa o limite superior da melhor testemunha de polinização aberta em cada local.

Figure 4. Values of the genetic gain of the parents in $\mathrm{DBH}(\mathrm{cm})$ at 15 years with the selection at the age of rotation (late selection) and with the selection at the age of 8 years (early selection), for the three sites, with the selection of the parents tested and statistically approved, with a maximum $n$ equal to 10 . The " $n$ " 'represents the number of parents used for the average when no parents were statistically approved. The dashed area represents the upper limit of the best open pollination control at each site. 
Coutinho et al. - Viabilidade da seleção precoce de Pinus taeda L. em

diâmetro a altura do peito em programa de melhoramento genético

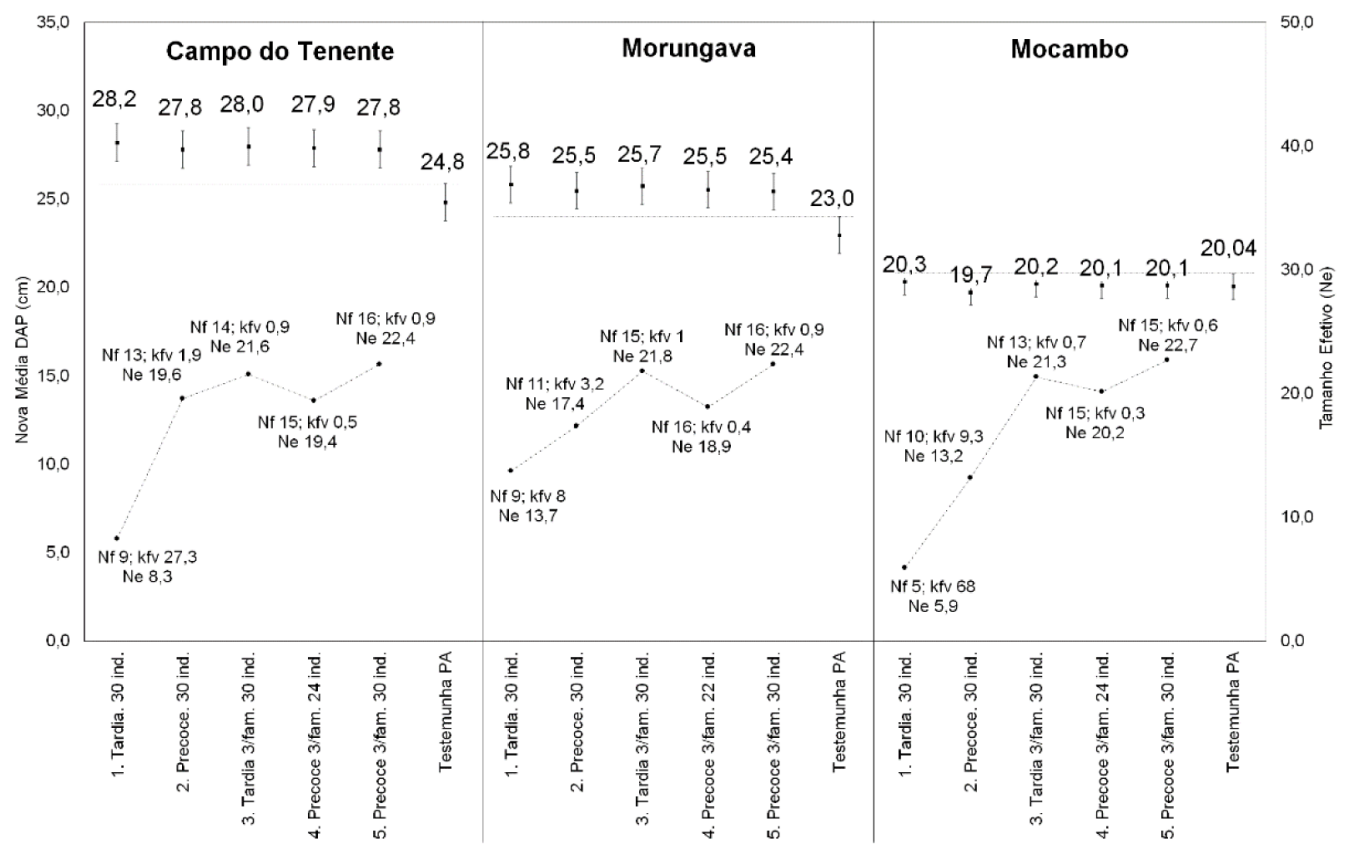

Figura 5. Valores do ganho genético dos genitores em DAP $(\mathrm{cm})$ aos 15 anos com a seleção na idade de rotação (seleção tardia) e com a seleção na idade de 8 anos (seleção precoce), para os três locais, com a seleção dos melhores indivíduos com e sem restrição de número de indivíduos por família. Estão apresentados também os valores referentes ao tamanho efetivo populacional ( $\mathrm{Ne}$ ) com número de famílias ( $\mathrm{Nf}$ ) e a variância do número de indivíduos por família $(\mathrm{kfv})$. O tracejado representa o limite superior da melhor testemunha de polinização aberta em cada local.

Figure 5. Values of the genetic gain of the parents in DBH $(\mathrm{cm})$ at 15 years with the selection at the age of rotation (late selection) and with the selection at the age of 8 years (early selection), for the three sites, with the selection of the best individuals with and without restriction of number of individuals per family. The values for the effective population size ( $\mathrm{Ne}$ ) with number of families ( $\mathrm{Nf}$ ) and the variance of the number of individuals per family ( $\mathrm{kfv}$ ) are also presented. The dashed represents the upper limit of the best open pollination control at each site.

\section{CONCLUSÕES}

Com base nos resultados obtidos pode-se concluir que:

- A seleção precoce dos dez melhores genitores selecionados de forma precoce foi eficaz apenas onde a seleção das matrizes e avaliação da progênie ocorreram no mesmo ambiente, ou seja, Campo do Tenente, PR.

- A seleção precoce de indivíduos foi eficaz para os ambientes com mesmo clima e fitogeografia do local de seleção das matrizes, ou seja, Campo do Tenente e Sengés, sendo recomendável a utilização da restrição de número de indivíduos máximo por família para evitar redução drástica no tamanho efetivo populacional.

- No ambiente com fitogeografia Cerrado não foi possível a seleção dos genitores e a seleção de indivíduos. Para este ambiente torna-se necessário a avaliação de novos germoplasmas.

\section{REFERÊNCIAS BIBLIOGRÁFICAS}

BALOCCHI, C. E.; BRIDGWATER, F. E.; ZOBEL, B. J.; JAHROMI, S. Age trends in genetic parameters for tree height in a non selected population of loblolly pine. Forest Science Bainbridge, GA. v. 39, n. 2, p. 231$251,1993$.

CPRM - COMPANHIA DE PESQUISA DE RECURSOS MINERAIS. Atlas Pluviométrico do Brasil. 2006. Disponível em: < http://www.cprm.gov.br >. Acesso em: 08 abr. 2015.

CUMMING, G.; FIDLER, F.; VAUX, D. L. Erro bars in experimental biology. The Journal of Cell Biology, Victoria, Australia. v. 177, n. 1, p. 7-11, 2007.

DIAS, L. A. S.; BARROS, W. S. Biometria experimental. Viçosa: Suprema, 2009. 408 p. 
DUDA, L. L. Seleção genética de árvores de Pinus taeda L. na região de Arapoti, Paraná. 2003,61 p. Dissertação (Mestrado em Ciências Florestais) - Universidade Federal do Paraná, Curitiba, 2003.

EMBRAPA - EMPRESA BRASILEIRA DE PESQUISA AGROPECUÁRIA. Sistema Brasileiro de Classificação de Solos. 3 ed. Brasília: Embrapa Solos, 2013. 353 p.

GWAZE, D. P.; BRIDGWATER, F. E.; BYRAM, T. D.; LOWE, W. J. Genetic Parameter estimates for growth and wood density in loblolly pine (Pinus taeda L.). Forest Genetics, Zvolen. v. 8, n.1, p.47-55, 2001.

GWAZE, D. P.; WOOLlIAMS, J. A.; KANOWSKI, P. J. Optimun Selection Age for Height in Pinus taeda L. in Zimbabwe. Silvae genetica, Frankfurt. v. 46, n.6. p. 358-365,1997.

IBÁ - INTITUTO BRASILEIRO DE ÁRVORES. Anuário estatístico do Instituto Brasileiro de Árvores IBÁ 2015 ano base 2014. Brasília: 2015. Disponível em: < http://www.iba.org >. Acesso em 10 abr. 2016.

MAACK, R. Geografia Física do Estado do Paraná. 3 ed. Curitiba: Imprensa Oficial, 2002. 440 p.

MARTINEZ, D. T.; RESENDE, M. D. V.; COSTA, R. B.; HIGA, A. R.; SANTOS, G. A.; FIER, I. S. N. Estudo da interação genótipo $\mathrm{x}$ ambiente em progênies de Pinus taeda por meio da análise de parâmetros genéticos. Revista Floresta, Curitiba, v. 42, n. 3, p. 539-552, 2012.

MINEROPAR. Mapa Geológico do Paraná. 2006. Disponível em: < http://www.mineropar.pr.gov.br >. Acesso em: 09 abr.2015.

PALUDZYSZYN FILHO, E.; FERNANDES, J. S. C.; RESENDE, M. D. V. Avaliação e seleção precoce para crescimento de Pinus taeda. Pesquisa Agropecuária Brasileira, Brasília, v. 37, n. 12, p. 1719-1726, 2002.

PIRES, I. E.; RESENDE, M. D. V.; SILVA, R. L.; RESENDE JÚNIOR., M. F. R. Genética Florestal. ViçOsa: UFV, 2011. 318 p.

RESENDE, M. D. V. Selegen-Reml/Blup: Sistema Estatístico e Seleção Genética Computadorizada via Modelos Lineares Mistos. Colombo: Embrapa Florestas, 2007. 360 p.

RESENDE, M. D. V. Melhor Predição Linear Não Viciada (BLUP) de Valores Genéticos no Melhoramento de Pinus. Boletim Pesquisa Florestal, Colombo, n. 32/33, p. 3-22. 1996 a.

RESENDE, M. D. V. Estimação de Componentes de Variância e Predição de Valores Genéticos pelo Método de Máxima Verossimilhança Restrita (REML) e Melhor Predição Linear Não Viciada (BLUP). Boletim Pesquisa Florestal, Colombo, n. 32/33, p. 23-42, 1996 b.

Recebido em 29/02/2016

Aceito para publicação em 17/11/2016

Sci. For., Piracicaba, v. 45, n. 113, p. 205-219, mar. 2017 DOI: dx.doi.org/10.18671/scifor.v45n113.21 